\title{
Upaya Peningkatan Kesehatan Lansia Melalui Senam Anti Hipertensi di Dusun Wanat Kecamatan Leihitu
}

\author{
Ernawati Hatuwe*1, Mirdat Hitiyaut ${ }^{2}$, Ratna Sari Rumakey ${ }^{3}$
}

1,2,3Program Studi Ilmu Keperawatan, STIKes Maluku Husada, Indonesia

*e-mail: $\underline{\text { hatuweernawati@gmail.com }}{ }^{1}$, $\underline{\text { mirdadhitiyaut@yahoo.com }}^{2}$

\begin{abstract}
Abstrak
Hipertensi merupakan salah satu penyakit berbahaya bagi lansia dan sering disebut sebagai the silent killer disease. Prevalensi hipertensi diwilayah Maluku pada tahun 2020 berjumlah 25.410 orang terkhususnya di Dusun Wanat sejumlah 35 orang. Berdasarkan fenomena yang terjadi di Dusun wanat lansia jarang melakukan aktifitas fisik dan memiliki kebiasaan mengkonsumsi garam berlebihan. Sehingga hal tersebut belum dapat mengatasi masalah hiperteni. Salah satu Intervensi yang dapat mengatasi maslaah tersebut yaitu dengan melakukan aktifitas fisik (Senam anti hipertensi). Tujuan kegiatan pengabdian ini yaitu upaya untuk kesehatan lansia melalui senam anti hipertensi yang dapat meningkatkan pengetahuan dan informasi tentang senam anti hipertensi agar dapat menurunkan tekanan darah dan mengurangi penderita hipertensi di Dusun Wanat. Metode yang digunakan yaitu ceramah dan demonstrasi senam anti hipertensi. Hasil lansia dapat mendemonstrasikan senam anti hipertensi dan peningkatan pengetahuan dengan kategori baik 14 orang (47\%), dan kategori tekanan darah 120-130 mmHg berjumlah 15 orang (50\%) selama dua minggu. Kesimpulan pengabdian ini memberikan peningkatakan pengetahuan dan senam anti hipertensi dapat menurunkan tekanan darah pada lansia yang mengalami hipertensi.
\end{abstract}

Kata Kunci: Hipertens, Lansia, Senam Anti Hipertensi

\begin{abstract}
Hypertension is a dangerous disease for the elderly and is often referred to as the silent killer disease. The prevalence of hypertension in the Maluku region in 2020 was 25,410 people, especially in Wanat Hamlet with 35 people. Based on the phenomenon that occurred in Wanat Hamlet, the elderly rarely do physical activity and have a habit of consuming excessive salt. So that it has not been able to overcome the problem of hypertension. One of the interventions that can overcome this problem is by doing physical activity (antihypertensive exercise). The purpose of this service activity is an effort for the health of the elderly through anti-hypertensive exercise which can increase knowledge and information about anti-hypertensive exercise in order to reduce blood pressure and reduce hypertension sufferers in Wanat Hamlet. The method used is lectures and demonstrations of anti-hypertension exercise. The results of the elderly can demonstrate antihypertensive exercise and increase knowledge in the good category of 14 people (47\%), and the blood pressure category of 120-130 $\mathrm{mmHg}$ totaling 15 people (50\%) for two weeks. The conclusion of this service is that it provides increased knowledge and anti-hypertensive exercise can reduce blood pressure in the elderly who have hypertension.
\end{abstract}

Keywords: Hypertensio,; Anti Hypertension Gymnastics, Elderly

\section{PENDAHULUAN}

Berdasarkan undang-undang nomor 36 tahun 2009 pasal 3 tentang kesehatan yang bertujuan meningkatkan derajat kesehatan, kesadaran, kemauan dan kemampuan hidup sehat bagi setiap masyarakat yang setinggi-tingginya, agar tercapainya pembangunan sumber daya manusia yang berguna secara sosial maupun ekonomis (Kementerian Kesehatan RI, 2009). Upaya untuk meningkatkan derajat kesehatan masyarakat salah satunya adalah dengan berperilaku hidup sehat, ini merupakan tujuan pembagunan kesehatan pada setiap individu. Dampak dari perubahan gaya hidup yaitu penyakit menular (PM) dan penyakt tidak menular (PTM) salah satunya seperti penyakit hipertensi yang harus diwaspadai (Long, Ponder, \& Bernard, 2017). Penyakit hipertensi merupakan faktor risiko utama dalam perkembangan penyakit kardiovaskular, termasuk stroke dan arteri koroner. Hipertensi didefinisikan sebagai penyakit kronis dimana tekanan darah sistolik lebih dari $140 \mathrm{mmHg}$ dan/atau diastolik tekanan 
darah lebih besar dari $90 \mathrm{mmHg}$, ini terjadi karena jantung berkeja lebih cepat untuk menyalurkan darah agar memenuhi kebutuhan oksigen keseluruh tubuh (Korsager Larsen \& Matchkov, 2016); (Boutcher \& Boutcher, 2017).

Hipertensi adalah penyakit umum yang membahayakan kesehatan masyarakat pada kelompok orang dewasa dan juga pada lansia yang biasa disebut sebagai the silent killer disease (Moreira et al, 2016). Menurut World Health Organization (WHO) 80\% dari populasi yang berusia 60 tahun atau lebih akan menderita hipertensi. Pada tahun 2019 penyakit jantung penyumbang kematian yang paling tinggi diseluruh dunia, sekitar 17,9 juta orang meninggal karena Cardiovascular diseases (CVD) pada 2019, 85\% disebabkan oleh serangan jantung dan stroke ini terjadi di negara-negara berpenghasilan rendah dan menengah, Negara Afrika memiliki angka hipertensi tertinggi sebesar 27\%, dan Asia Tenggara menduduki peringkat ke-3 sebesar 25\% terhadap total penduduk (Vardell, 2020). Berdasarkan data dari Riskesdas tahun 2018 prevalensi hipertensi di Indonesia pada penduduk $>18$ tahun sebesar $34,11 \%$, berdasarkan jenis kelamin perempuan memiliki proporsi hipertensi lebih tinggi (36,85\%) dibandingkan laki-laki (31,34\%). Data berdasarkan kota, penderita hipertensi yang paling tinggi terdapat di Kalimantan Selatan sebesar 44,13\%, dan Maluku sebesar 28,99 \% (Infodatin, 2019).

Berdasarkan data dari Pusdatin Dinkes Provinsi Maluku (2021) hipertensi termasuk sepuluh penaykit terbesar di Maluku ini terlihat pada tiga tagun terahkir. Tahun 2018 hipertensi menduduki peringkat ke empat sebanyak 14.789 penderita, tahun 2019 hipertensi menurun menjadi peringkat ke sembilan sebanyak 1.810 penderita dan pada tahun 2020 hipertensi meningkat menduduki peringkat ke empat dengan jumlah penderita sebanyak 25.410, penyakit ini sering ditemukan pada usia lanjut sehingga menyebabkan disabilitas. Hipertensi adalah penyakit yang paling umum di dunia pada lansia, tetapi ada kemungkinan untuk mengubahnya, upaya yang dapat mengurangi penderita hipertensi yaitu dengan melakukan aktivitas fisik seperti senam anti hipertensi. Ini telah dibuktikan oleh (Sartika et al, 2020) hasil penelitiannya menunjukan bahwa ada pengaruh senam lanjut usia terhadap penurunan tekanan darah pada penderita hipertensi. Ini sejalan dengan penelitian (Sharman, La Gerche, \& Coombes, 2015) lansia yang menderita hipertensi yang kurang aktif secara fisik akan terkena kolesterol dan stroke dibandingkan lansia yang menderita hipertensi selalu melakukan aktivitas fisik (olahraga) mampu menurunkan tekanan darah tinggi.

(Gomes et al., 2016) menjelaskan bahwa olahraga sebagai terapi anti hipertensi yang dapat menurunkan tekanan darah sebesar 1 hingga $5 \mathrm{mmHg}$ pada penderita hipertensi, ini dapat dilakukan kurang lebih 12 minggu, seminggu dapat dilakukan 3-4 kali selama kurang lebih 40 menit. (Ferrari et al., 2017) menjelaskan bahwa olahraga sebagai intervensi untuk pasien hipertensi terutama pada usia lanjut. Ini sangat direkomendasikan karena selain menurunkan tekanan darah juga dapat memperkuat massa otot dan kebugaran jasmani pada kelompok lansia.

Aktifitas Fisik (Senam anti hipertensi) adalah olahraga yang bertujuan untuk meningkatkan aliran darah dan oksigen kedalam otot jantung. (Mahardani, 2010 dalam Hernawan \& Rosyid, 2017) menjelaskan bahwa dengan senam kebutuhan oksigen dalam sel akan meningkat untuk proses pembentukan energi, sehingga terjadi peningkatan denyut jantung, dan curah jantung, dengan demikian tekanan darah akan meningkat. Setelah berisitirahat pembuluh darah akan berdilatasi atau melebar, dan aliran darah akan turun sementara waktu, sekitar 30-120 menit kemudian akan kembali pada tekanan darah sebelum senam. Jika senam dilakukan secara rutin, kemungkinan besar tekanan darah akan bertahan lebih lama dan pembuluh darah akan lebih elastis. Penurunan tekanan darah setelah berolahraga dapat merilekskan pembuluh-pembuluh darah, juga melebarnya pembuluh darah sehingga tekanan darah akan turun.

Hasil observasi dan wawancara di Dusun Wanath RT 001, 002 dan 003 Kecamatan Leihitu, banyak masyarakat khususnya lansia yang menderita hipertensi dan stroke. Beberapa lansia mengatakan jarang melakukan olahraga, mereka hanya beraktivitas didalam rumah seperti memasak, dan bersih-bersih dan mereka banyak mengkonsumsi garam berlebihan. Berdasarkan permasalahan diatas, maka perlu dilakukan pengabdian masyarakat penyuluhan tentang senam anti hipertensi dan kegiatan demonstrasi kepada lansia. Tujuan pengabdian ini 
yaitu upaya untuk kesehatan lansia melalui senam anti hipertensi yang dapat meningkatkan pengetahuan dan informasi tentang senam anti hipertensi agar dapat menurunkan tekanan darah dan mengurangi penderita hipertensi di Dusun Wanath RT 001, 002 dan 003 Kecamatan Leihitu

\section{METODE}

Metode yang digunakan dalam pengabdian ini yaitu ceramah dan demostrasi senam anti hipertensi Pelaksanaan pengabdian masyarakat dilakukan di balai Dusun Wanath RT 001, 002 dan 003 Kecamatan Leihitu. Sasaran kegitan pengabdian masyarakat ini adalah lansia yang berjumlah 20 orang dengan mengikut sertakan mahasiswa. Tahapan kegiatan ini terbagi atas tiga tahap yaitu:

a. Tahap persiapan: Media yang digunakan infokus, leaflet, speaker, tensimeter, peserta dianjurkan menggunakan masker dan handsanitizer.

b. Tahap pelaksanaan: Pretest peserta sebelum mengikuti kegiatan peserta dilakukan screening mulai dari menanyakan nama, umur, jenis kelamin, alamat dan mengukur tekanan darah. Dan peserta diberikan kuesioner tentang hipertensi yang berisi pengertian hipertensi, faktor penyebab, tanda gejala, sampai dengan intervensi. Penyuluhan tentang senam anti hipertensi, pembagian lieflet, tanya jawab untuk merespon pemahaman peserta dan video senam anti hipertensi, demonstrasi senam hipertensi dipandu oleh instruktur.

c. Tahap evaluasi: Posttest Dilakukan pada minggu ke dua, peserta diberikan kuesioner dan peserta berkesempatan untuk melakukan atau mendemonstrasikan senam anti hipertensi mandiri tanpa dipandu.

\section{HASIL DAN PEMBAHASAN}

Pengabdian masyarakat dilaksanakan pada tanggal 6 Juli 2021 dengan jumlah peserta 20 orang lansia yang memiliki riwayat hipertensi. Pada tahap pertama tim pengabdian melakukan pemeriksaan kesehatan pada peserta yang meliputi pemeriksaan tekanan darah. Setelah semua peserta dilakukan pemeriksaan kesehatan peserta diminta berkumpul di Balai Desa untuk diberikan penyuluhan pengetahuan tentang meningkatkan kesehatan lansia melalui senam anti hipertensi. Jumlah peserta sebanyak 20 orang.

\subsection{Kegiatan screening Hipertensi}

Setiap warga yang hadir didata mulai dari nama usia, jenis kelamin, alamat dan pemeriksaan tekanan darah.

Tabel 1. Karakteristik Responden Berdasarkan Umur

\begin{tabular}{ccc}
\hline Usia & $\mathbf{n}$ & $\mathbf{\%}$ \\
\hline $45-54$ & 9 & 30 \\
$60-74$ & 18 & 60 \\
$75-90$ & 3 & 10 \\
\hline Total & $\mathbf{3 0}$ & $\mathbf{1 0 0}$ \\
\hline
\end{tabular}

Sumber: Data Primer 2021

Dari Tabel 1 dapat diketahui mayoritas responden paling banyak lansia berusia 60-74 tahun dengan jumlah 18 orang (60\%), lansia usia 45-54 tahun sebanyak 9 orang (30\%), dan lansia yang berusisa 75-90 tahun sebanyak 3 orang (10\%). Hipertensi pada lansia mempunyai prevalensi yang tinggi, pada usia diatas 60 tahun didapatkan antara 60\%. Sekitar 60\% hipertensi pada usia lanjut adalah hipertensi sistolik terisolasi (Isolated Systolic Hypertension) dimana terdapat kenaikan tekanan darah sistolik disertai penurunan tekanan darah diastolik. Peningkatan tekanan darah sistolik disebabkan terutama oleh kekakuan arteri atau berkurangnya elastisitas aorta (Boutcher \& Boutcher, 2017). 
Tabel 2. Karakteristik Responden Berdasarkan Jenis Kelamin

\begin{tabular}{ccc}
\hline Jenis Kelamin & $\mathbf{N}$ & $\mathbf{\%}$ \\
\hline Laki-Laki & 8 & 27 \\
Perempuan & 22 & 73 \\
\hline Total & $\mathbf{3 0}$ & $\mathbf{1 0 0}$
\end{tabular}

Sumber: Data Primer 2021

Tabel 2 menunjukkan bahwa mayoritas responden paling banyak adalah berjenis kelamin perempuan dengan jumlah 22 orang (73\%), jenis kelamin laki-laki sejumlah 8 orang $(27 \%)$. Hasil ini sejalan dengan penelitian (Caseey\&Benson, 2006) dalam (Aristoteles, 2018) laki-laki sering mengalami tanda - tanda hipertensi pada usia akhir 30 tahun, sedangkan wanita sering mengalami hipertensi setelah manepouse. Tekanan darah wanita, khususnya sistolik, meningkat lebih tajam sesuai usia. Setelah 55 tahun, wanita memang mempunyai risiko lebih tinggi untuk menderita hipertensi. Salah satu penyeb terjadinya pola tersebut adalah perbedaan hormon kedua jenis kelamin. Peroduksi hormon estrogen menurun saat manepouse, wanita kehilangan efek menguntungkan nya sehingga tekanan darah meningkat.

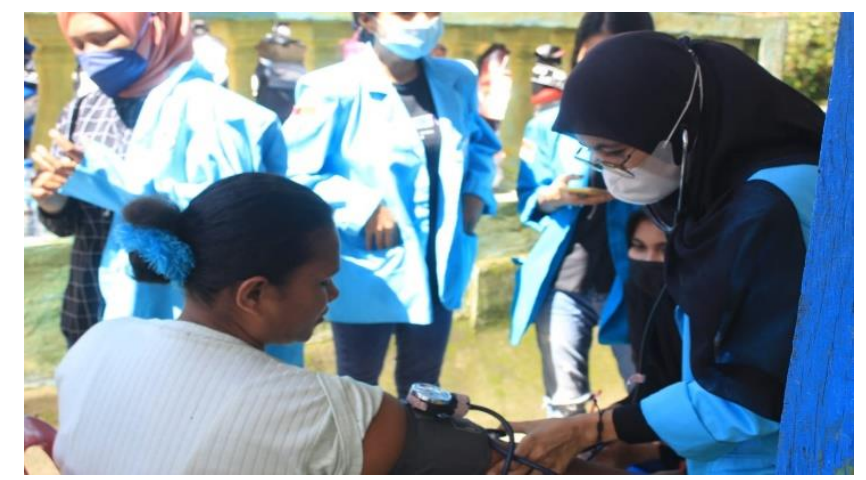

Gambar 1. Kegiatan Screening Hipertesi

\subsection{Kegiatan Edukasi Kesehatan}

Pemberian edukasi ini dilaksanakan dengan pemberian materi melalui ceramah dan diskusi serta pembagian leaflet dan video senam anti hipertensi. Dilanjutkan dengan praktik latihan atau mendemostrasikan senam anti hipertensi. Proses evaluasi (pre test dan post test) pada seluruh peserta menggunakan lembar pernyataan yang harus diisi oleh peserta kegiatan. Soal pre dan post test tersebut diberikan untuk mengetahui pengetahuan peserta yang menderita hipertensi yaitu meliputi pemahaman tentang tujuan dan perencanaan tindakan yang berkaitan dengan perilaku diet makanan (garam, makanan yang banyak mengandung minyak).

Tabel 3. Distribusi Frekuensi Pretest Pengetahuan Lansia Tentang intervensi pada penderita Hipertensi Di Dusun Wanath RT 001, 002 dan 003 Kecamatan Leihitu

\begin{tabular}{ccc}
\hline Tingkat Pengetahuan & n & \% \\
\hline Baik & 5 & 16, \\
Cukup & 10 & 34 \\
kurang & 15 & 50 \\
\hline Total & $\mathbf{3 0}$ & $\mathbf{1 0 0}$
\end{tabular}

Sumber: Data Primer 2021

Berdasarkan Tabel 3 dapat dilihat bahwa hasil pretest 5 pertanyaan para peserta sebelum diberikan informasi atau penjelasan menunjukkan 30 orang dari peserta (100\%) memperoleh nilai mayoritas peserta memiliki nilai kurang sejumlah 15 orang (50\%). Tabel 4 menunjukan bahwa pada posttest memiliki nilai baik sebanyak 14 orang (47\%) yang memiliki nilai cukup sebanyak 11 orang (37\%). Tabel 3 dan 4 menunjukan bahwa terjadi peningkatan pengetahuan yang signifikan. Sejalan dengan penelitian (Sharman, 2015) pendidikan atau penyuluhan dapat 
memberikan pemahan dan informasi kepada masyarakat yang mengalami masalah yang dalam hal ini adalah hipertensi pada lansia, sehingga keluarga atau pun penderita dapat mencegah dan mengobati masalah tersebut.

Tabel 4. Distribusi Frekuensi Postest Pengetahuan Lansia Tentang intervensi pada penderita Hipertensi Di Dusun Wanath RT 001, 002 dan 003 Kecamatan Leihitu

\begin{tabular}{c|c|c}
\hline Tingkat Pengetahuan & n & $\mathbf{\%}$ \\
\hline Baik & 14 & 47 \\
\hline Cukup & 11 & 37 \\
\hline Kurang & 5 & 16 \\
\hline Total & $\mathbf{3 0}$ & $\mathbf{1 0 0}$ \\
\hline
\end{tabular}

Terjadi Sumber: Data Primer 2021

\subsection{Demonstrasi Senam Anti Hipertensi}

Demonsrasi senam anti hipertensi. Pelatihan tersebut menggunaakn alat peraga yaitu berupa video dan peragaan gerakan langsung oleh instruktur. Mengajarkan senam anti hipertensi sesuai dengan standar operasional prosedur. Senam anti hipertensi dilaksanakan selama 20-30 menit.

Tabel 5. Karakteristik tekanan Darah Penderita Hipertensi Sebelum Melakukan Senam Anti Hipertensi

\begin{tabular}{ccc}
\hline $\begin{array}{c}\text { Kategori TD Sebelum } \\
\text { Senam Anti Hipertensi }\end{array}$ & $\mathbf{n}$ & $\mathbf{\%}$ \\
\hline $120-130 \mathrm{mmHg}$ & 6 & 20 \\
$139-159 \mathrm{mmHg}$ & 10 & 33 \\
$>160 \mathrm{mmHg}$ & 14 & 47 \\
\hline Total & $\mathbf{3 0}$ & $\mathbf{1 0 0}$ \\
\hline
\end{tabular}

Sumber: Data Primer 2021

Tabel 5 terlihat bahwa tekanan darah seluruh penderita sebelum melakukan senam anti hipertensi dengan kategori $>160 \mathrm{mmHg} 14$ orang (47\%). Tekanan darah yang relatif tinggi ini dipengaruhi oleh beberapa faktor diantaranya lansia yang jarang melakukan aktifitas fisik (Olahraga) dan banyak mengkonsumsi makanan yang tinggi garam hal ini sesuai dengan penelitian yang dilakukan oleh (Aristoteles, 2018) hasil penelitiannya menjelaskan bahwa terjadinya peningkatan tekanan darah akibat dari pola hidup yang kurang sehat misalnya sering mengkonsumsi rokok, jarang tidur malam, kurang aktifitas fisik dan sering mengkonsumsi makanan yang tinggi garam. Setelah melakukan senam anti hipertensi penderita dilakukan post test pemeriksaan tekanan darah kembali setelah tiga minggu berlalu.

Tabel 6. Karakteristik tekanan Darah Penderita Hipertensi Sesudah Melakukan Senam Anti Hipertensi

\begin{tabular}{ccc}
\hline $\begin{array}{c}\text { Kategori TD Sebelum } \\
\text { Senam Anti Hipertensi }\end{array}$ & $\mathbf{n}$ & $\mathbf{\%}$ \\
\hline $120-130 \mathrm{mmHg}$ & 15 & 50 \\
$139-159 \mathrm{mmHg}$ & 9 & 30 \\
$>160 \mathrm{mmHg}$ & 6 & 20 \\
\hline Total & $\mathbf{3 0}$ & $\mathbf{1 0 0}$ \\
\hline
\end{tabular}

Sumber: Data Primer 2021

Tabel 6 menunjukkan bahwa mayoritas TD penderita sesudah melakukan senam anti hipertensi dengan kategori TD 120-130 mmHg berjumlah 15 orang (50\%), kategori TD 139-159 mmHg 9 orang (30\%) dan kategori TD >160 mmHg 6 orang (20\%). Hal ini terlihat bahwa tekanan darah mengalami penurunan artinya lansia rutin dan benar melakukan senam anti hipertensi di rumah. Ini sejalan dengan penelitian yang dilakukan (Elviana, 2021) bahwa selain 
menjaga makanan yang banyak mengandung garam, mengkonsumsi obat hipertensi, aktivitas fisik (senam anti hipertensi) dapat menurunkan tekanan darah pada lansia.

Senam anti hipertensi ada 18 gerakan yang mudah dilakukan oleh lansia, waktu kurang lebih 30 menit. Dimulai dengan gerakan jalan ditempat, tepuk telapak tangan kanan dan kiri, tepuk jari-jari tangan kanan dan kiri, pertemukan sela-sela jari tangan kanan dan kiri, pertemukan ibu jari kanan dan kiri dengan arah menyilang, buka telapak tangan menghadap ke atas, dan pertemukan kelingking kanan dan kiri, buka telapak tangan menghadap ke bawah, dan pertemukan sisi telunjuk kanan dan kiri, rentangkan kedua tangan kedepan, lalu ketuk pergelangan tangan kanan dan kiri secara bergantian, satukan kedua telapak tangan dan satukan jari-jari lalu gerakan kedepan dan kebelakang, rentangkan kedua tangan lalu kepal dan buka jari-jari tangan, rentangkan tangan kedepan lalu tepuk punggung tanga kanan dan kiri secara bergantian, rentangkan tangan kedepan lalu tepuk lengan dan bahu kanan dan kiri secara bergantian, dengan posisi berdiri agak membungkuk tepuk pinggang dengan kedua tangan, dengan posisi berdiri tepuk paha kanan dan kiri dengan kedua tangan, dengan posisi kedua tangan di rentangkan kedepan, lalu naik turun kebawah dengan posisi setengah jongkok dan berdiri, tepuk perut dengan kedua tangan secara bergantian dan posisi berdiri tegap dan kedua tangan berada di depan perut, lalu lakukangerakan menjinjit.

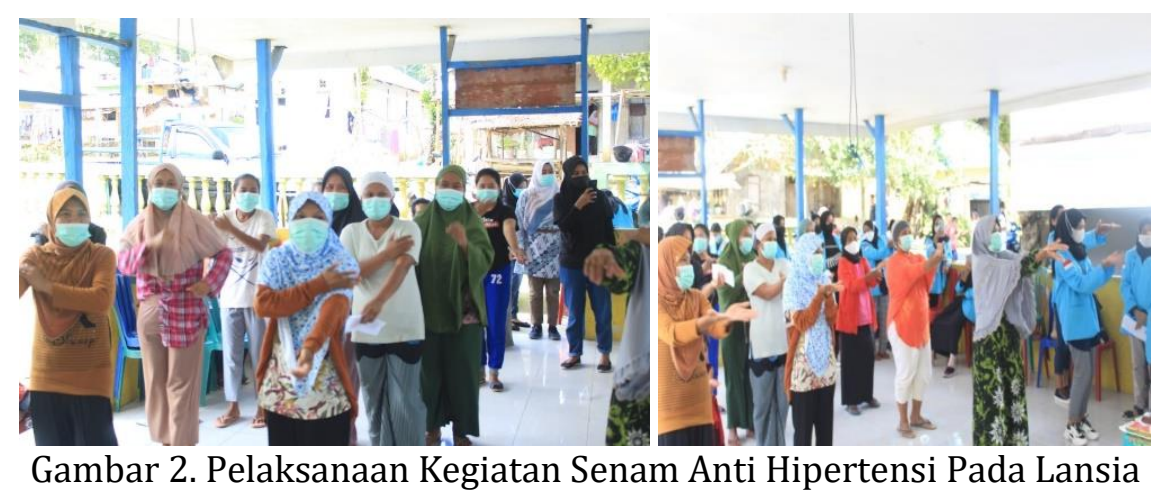

Akhir dari kegiatan senam anti hipertensi, peserta memahami semua gerakan dengan mudah tanpa dipandu instruktur senam. Setelah itu peserta ditanyakan bagaimana perasaannya setelah melakukan kegiatan ini, 12 peserta lansia mengatakan senang dengan adanya kegiatan senam, badan merasa lebih ringan, badan berkeringat dan merasa lebih segar. Senam anti hipertensi dapat meningkatkan jumlah volume darah atau curah jantung sehingga terjadinya sirkulasi oksigen seleruh bagian tubuh (Elviana, Astuti, Fandizal, \& Sani, 2021).

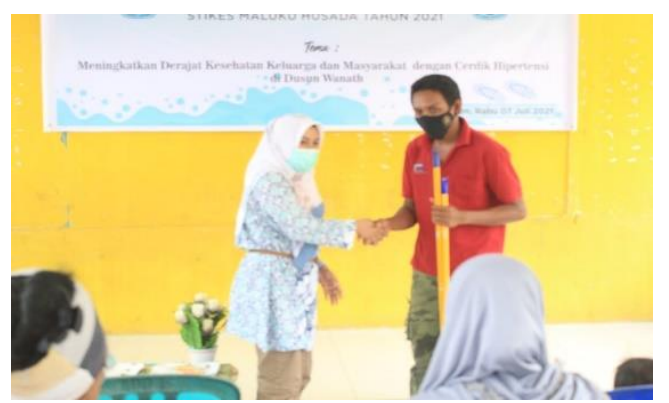

Gambar 3. Penyerahan Cindramata

\section{KESIMPULAN}

Dari hasil pengabdian masyarakat yang didapatkan bahwa sebagian peserta sudah mengetahui penyakit hipertensi dari pengertian sampai dengan intervensi yang dapat dilakukan untuk menurunkan tekanan darah dan senam anti hipertensi. Kegiatan berjalan dengan baik, semua peserta lansia sangat antusias mengikuti kegiatan sampai akhir, dan lansia dapat 
melakukan senam anti hipertensi tanpa dipandu. Peserta diberikan kuesioner juga dilakukan dilakukan pemeriksaan tekanan darah setelah tiga minggu mereka melakukan senam mandiri tanpa pemandu didapatakan kategori TD 120-130 mmHg berjumlah 15 orang (50\%), kategori TD 139-159 mmHg 9 orang (30\%) dan kategori TD >160 mmHg 6 orang (20\%). Hal ini terlihat bahwa tekanan darah mengalami penurunan artinya lansia rutin dan benar melakukan senam anti hipertensi di rumah.

\section{DAFTAR PUSTAKA}

Aristoteles. 2018. “Korelasi Umur Dan Jenis Kelamin Dengan Penyakit Hipertensi Di Emergency Center Unit Rumah Sakit Islam Siti Khadijah Palembang 2017.” Indonesia Jurnal Perawat.

Boutcher, Y. N., \& Boutcher, S. H. (2017). Exercise intensity and hypertension: What's new? Journal of Human Hypertension. https://doi.org/10.1038/jhh.2016.62

Elviana, N., Astuti, Y., Fandizal, M., \& Sani, D. N. (2021). Pelatihan Senam Hipertensi Pada Lansia. 02(01), 4-7.

Ferrari, R., Umpierre, D., Vogel, G., Vieira, P. J. C., Santos, L. P., de Mello, R. B., ... Fuchs, S. C. (2017). Effects of concurrent and aerobic exercises on postexercise hypotension in elderly hypertensive men. Experimental Gerontology.https://doi.org10.1016/j.exger. 2017.08.012

Gomes, S. G., Silva, L. G., Santos, T. M., Totou, N. L., Souza, P. M., Pinto, K. M. C., ... Becker, L. K. (2016). Elderly hypertensive subjects have a better profile of cardiovascular and renal responses during water-based exercise. Journal of Exercise Physiology Online, 19(4), 2131.

Harber, M. P., Konopka, A. R., Douglass, M. D., Minchev, K., Kaminsky, L. A., Trappe, T. A., \& Trappe, S. (2009). Aerobic exercise training improves whole muscle and single myofiber size and function in older women. American Journal of Physiology - Regulatory Integrative and Comparative Physiology. https://doi.org/10.1152/ajpregu.00354.2009

Hernawan, T., \& Rosyid, F. N. (2017). Pengaruh Senam Hipertensi Lansia terhadap Penurunan Tekanan Darah Lansia dengan Hipertensi di Panti Wreda Darma Bhakti Kelurahan Pajang Surakarta. Jurnal Kesehatan. https://doi.org/10.23917/jurkes.v10i1.5489

Infodatin. (2019). Hipertensi Si Pembunuh Senyap. Kementrian Kesehatan RI. https:// pusdatin.kemkes.go.id/di akses pada tanggal 11 Agustus 2021 pukul 22.30 WIB

Kementerian Kesehatan RI. (2009). UU RI No 36 Tahun 2009 Tentang Kesehatan. Journal of Agricultural and Food Chemistry.

Korsager Larsen, M., \& Matchkov, V. V. (2016). Hypertension and physical exercise: The role of oxidative stress. Medicina (Lithuania). https://doi.org/10.1016/j.medici.2016.01.005

Long, E., Ponder, M., \& Bernard, S. (2017). Knowledge, attitudes, and beliefs related to hypertension and hyperlipidemia self-management among African-American men living in the southeastern United States. Patient Education and Counseling.https://doi.org/10. 1016/j.pec.2016.12.011

Moreira, S. R., Cucato, G. G., Terra, D. F., \& Ritti-Dias, R. M. (2016). Acute blood pressure changes are related to chronic effects of resistance exercise in medicated hypertensives elderly women. Clinical Physiology and Functional Imaging. https://doi.org/10.1111/cpf.12221

Sartika, A., Betrianita, B., Andri, J., Padila, P., \& Nugrah, A. V. (2020). Senam Lansia Menurunkan Tekanan Darah pada Lansia. Journal of Telenursing (JOTING). https://doi.org/10.31539/ joting. v2i1.1126

Sharman, J. E., La Gerche, A., \& Coombes, J. S. (2015). Exercise and cardiovascular risk in patients with hypertension. American Journal of Hypertension.https://doi.org/10.1093/ajh/ hpu191

Vardell, E. (2020). Global Health Observatory Data Repository. Medical Reference Services Quarterly, 39(1), 67-74. https://doi.org/10.1080/02763869.2019.1693231 


\section{Halaman Ini Dikosongkan}

